\title{
Issues of context and design in OER (open educational resources)
}

\author{
Ferit Kılıçkaya $^{1}$ (D) · Joanna Kic-Drgas ${ }^{2}$
}

Accepted: 22 October 2020 / Published online: 23 November 2020

(c) Association for Educational Communications and Technology 2020

\begin{abstract}
The study conducted by Hilton (2016) focused on open educational resources (OER) by analyzing the findings of 16 studies that investigated (a) the influence of OER on academic learning outcomes at the tertiary context, and (b) students' and instructors' perceptions of OER in their teaching and learning contexts. Hilton's analysis of the findings of these studies indicated two major findings: (1) when students use OER, they obtain the same learning outcomes as with traditional textbooks while saving money; and (2) both students and teachers find OER comparable to traditional learning resources in terms of quality. Several advantages of OER were also revealed. These included low or no cost of OER, perceived ease of reading and access, their ability to provide the same learning outcomes as traditional materials, and students' and instructors' positive perceptions. By indicating the role of OER in obtaining the same or similar learning, the study has also suggested that OER be considered useful sources for classes and also a valid replacement for commercial textbooks. However, we also need to consider the context where OER will be used and how OER are designed and used in this context since these two determine whether OER will work and suffice. This article considers the contextual factors and design of OER, and the limitations of Hilton's work in addition to several ideas and suggestions for further research regarding OER in online and face-to-face instruction.
\end{abstract}

Keywords Open educational resources · OER · Design · Contextual factors

\section{Introduction}

Open Educational Resources (OER) are learning materials that may be used in the teaching and learning contexts according to the $5 \mathrm{Rs}$ (retain, reuse, revise, remix, or redistribute) and recognized by all stakeholders as an invaluable means to allow inclusive and equitable gain to information and learning (Kawachi 2014). The recent shift to online learning

Ferit Kılıçkaya

ferit.kilickaya@gmail.com

Joanna Kic-Drgas

j.drgas@amu.edu.pl

1 Burdur Mehmet Akif Ersoy University, Burdur, Turkey

2 Adam Mickiewicz University, Poznań, Poland 
and teaching, especially during the COVID-19 pandemic, has increased the need for more online and open sources (Schaffhauser 2020).

OER seem to provide a wealth of opportunities for teachers, learners, administrators, and institutions. Quite a few instructors benefit from OER in their courses due to their perceived low-cost, ease of access, and flexibility (Hilton 2016). OER has great potential in ESP (English for Specific Purposes). On the one hand, the specialization of many fields diversified needs of ESP learners makes it difficult to develop efficient and "tailor-made" traditional coursebooks. Therefore, using OER in educational settings has also gained the attention of researchers, leading to studies on the effectiveness of OER, teacher and learner perceptions of these materials, and their related benefits. To date, studies have promulgated that OER are positively perceived by teachers and instructors, and that they are as effective as traditional or commercial textbooks and materials (Hilton 2016; Hilton 2020; Delgado et al. 2019; Shams et al. 2020; Orton Grissett and Huffman 2019).

\section{Impact and issues}

Of these studies, Hilton's is especially noteworthy as it reviews 16 studies pertaining to student learning outcomes and student and teacher perceptions of OER and commercial textbooks in an era when many are shifting to using widely available digital resources. The results of these studies indicate two main findings: (a) when students use OER, they obtain the same learning outcomes as with traditional textbooks while saving money; and (b) both students and teachers find OER comparable to traditional learning resources in terms of quality.

As a result of Hilton's study synthesizing the results of these 16 studies on OER and commercial textbooks, several advantages of OER are clarified. These include their low cost, perceived ease of reading and access, their ability to provide the same learning outcomes as traditional materials and students' and instructors' positive perceptions. By indicating the role of OER in obtaining the same or similar learning, the study has also suggested that OER be considered useful sources for classes and also a valid replacement for commercial textbooks. This also might lead to the idea that OER offers the ability to students and instructors to benefit from resources that are impossible considering the high cost of source materials commercially available (Grimaldi et al. 2019).

The major benefits of OER, namely, cost and access, appear as the leading factors that significantly influence instructors' and students' interest and motivation for using OER (Luo et al. 2020; Hurley and Hallmark 2020; Open Education Week 2020) since the high cost of access to necessary and good resources might inhibit obtaining knowledge and practice. Additionally, the OER materials can be easily updated, modified and shared which leads to inclusive, open and participatory education, saving time teachers significant time and effort on resource development (de Oliveira Neto et al. 2017). As such, indicating the potential role of OER as a class of resource compared with textbooks, Hilton's study requires that OER be further investigated in several other aspects and issues such as context, design, and quality.

It should, as a response, be noted that the perceived benefits of OER might be different for different contextual factors. We need to ask several questions before selecting and designing OER. These include but not limited to:

- Which subjects are students studying and at which educational level are they? 
- At which education level are learners studying their subjects?

- Is the course online or face-to-face in the classroom?

- What are the financial circumstances? Can learners afford commercial resources?

- Do we have access to software appropriate for the level of the students?

- Will there be access to the Internet or other communication devices?

- What are the technical devices and tools available in the teaching and learning context?

- Can learner agency be promoted? How can learners contribute to selecting and adapting print/online OER?

- Are teachers prepared to work with OER?

- Can the materials be updated, modified?

For example, social science students and female students have a better perception of the benefits of OER than those in other academic disciplines and OER might be as effective as commercial textbooks and learning materials or even better at producing the desired learning outcomes (Shams et al. 2020). This finding may well encourage OER adoption. However, their potential may remain largely unrealized or under-realized due to the issues considered in this review: (a) context, (b) design, and (c) OER content and implementation quality.

In the era of technology and widely available digital resources, it is crucial to weld context, OER content, and quality of implementation together. However, the current state seems to be a mixed bag and remains a high-priority quest for instructors and learners. When one probes into OER, it can be observed that some OER are well-designed in terms of being accessible, flexible, remixable, and aesthetically pleasing. However, it is also noticeable that some others are poorly designed and thereby poorly used. The studies reviewed in Hilton's (2016) article do not seem to probe into any details about the learning materials used in the study on their content and implementation. Omitting this invaluable information is too common in OER efficacy studies.

Some of the studies in Hilton's article aim to explain the pedagogical reasons put forward and decisions made considering OER adoption over traditional or commercial textbooks, but these studies rarely name the commercial textbooks used for comparison. Another point to be made on Hilton's article is that it treats all OER equally. It is important to explain how OER are used or presented to learners. In other words, the article does not probe the qualities necessary to make OER good or what they should include (e.g. visual and auditory materials). OER often include a digital textbook or the digitized version of print materials. In some cases, OER appear as electronic learning modules supported with multimedia such as images, animations, and videos. One can state that different OER might work better or worse in different contexts, for different subjects and at different levels. However, we also need to consider the context where OER will be used and how OER are designed and used in this context since these two determine whether OER will work and suffice. OER are not standardized pertaining to design. In other words, when teachers and learners search for OER covering a certain topic, they may find materials ranging from static, one- or multiple-page PDF file(s) to developed websites that can be accessed from mobile devices without losing their interactive features. We cannot find discussions or reviews of the design of OER in the studies reviewed in Hilton's article, and readers are not provided with information about the design of the activities and materials in commercial textbooks, either. We need to consider the design of these materials and resources, as it may heavily influence how they can be used for the 5Rs and how they are integrated into classroom practices (e.g. it can be almost impossible for instructors to remix multimedia files or PDF files even if they are allowed to do so). 


\section{Application}

Since contextual factors and design play a crucial role in selecting and designing, there are several points to consider before designing the learning environment and the activities. The contextual factors must be considered thoroughly in addition to the available technological devices and tools that both students and teachers have and/or access in their learning and teaching environments. For example, the Internet speed, quota, and the access of frequency might limit the usability of videos in online or face-to-face instruction since learners might be restricted in terms of download quota. In such cases, the quality of videos might be decreased, or audio-only versions might be used if the focus is the content rather than nonverbal signals such as body language. Texts might be shared through PDF files, and their size could be reduced to allow faster viewing and easier access. Moreover, learner agency can also be promoted by involving them in the decision process, and suggestions and/or other OER resources might be elicited rather than the inputs transmitted from the teacher to the learner. This can be done through a quick survey in large classes.

\section{Conclusion}

Teachers' willingness to use OER results from the possible opportunity to increase learning experiences and make learning more accessible for learners who cannot afford or access commercial textbooks or sources (Krajka 2018; Van Allen and Katz 2020). Adopting OER may require significant effort from teachers who work alone and teach multiple classes. During the process of adoption, it is necessary to consider the local context, content, selection and design OER accordingly. Creating a multimedia learning environment with remixed images and videos might be necessary to present the content to learners in a variety of ways. Therefore, in further research, in online, blended, or face-to-face classrooms, it is imperative to consider contextual factors and the design of these resources while deciding on the adoption of OER and how they should be presented (e.g. decisions about using images to help learners understand the concepts; understanding which demonstrations can be used and combined). Besides, as indicated by Wiley and Hilton (2018), we must move the direction of research towards criteria on OER context, design, and quality to encourage the use of innovative pedagogical practices to make use of these resources in learning.

\section{Compliance with ethical standards}

Conflicts of interest The manuscript has no potential conflicts of interest.

Informed consent Therefore, no informed consent is necessary.

Research involving human and/or animal participants The manuscript does not involve any human participants and/or animals. 


\section{References}

de Oliveira Neto, J. D., Pete, J., Daryono, \& Cartmill, T. (2017). OER use in the Global South: A baseline survey of higher education instructors. In C. Hodgkinson-Williams \& P. B. Arinto (Eds.), Adoption and impact of OER in the Global South (pp. 69-118). https://doi.org/10.5281/zenodo.599535.

Delgado, H., Delgado, M., \& Hilton, J., III. (2019). On the efficacy of open educational resources: Parametric and nonparametric analyses of a university calculus class. The International Review of Research in Open and Distributed Learning, 20(1), 185-203. https://doi.org/10.19173/irrodl.v20i1.3892.

Grimaldi, P. J., Mallik, D. B., Waters, A. E., \& Baraniuk, R. G. (2019). Do open educational resources improve student learning? Implications of the access hypothesis. PLoS One, 14(3), e0212508. https:// doi.org/10.1371/journal.pone.0212508.

Hilton, J., III. (2016). Open educational resources and college textbook choices: A review of research on efficacy and perceptions. Educational Technology Research and Development, 64(4), 573-590. https:// doi.org/10.1007/s11423-016-9434-9.

Hilton, J., III. (2020). Open educational resources, student efficacy, and user perceptions: A synthesis of research published between 2015 and 2018. Educational Technology Research and Development, 68(3), 853-876. https://doi.org/10.1007/s11423-019-09700-4.

Hurley, T. A., \& Hallmark, J. R. (2020). Inclusive access and open educational resource programs: A system perspective. In T. A. Hurley (Ed.), Inclusive access and open educational resources: E-text programs in higher education (pp. 3-14). Springer Nature. https://doi.org/10.1007/978-3-030-45730-3.

Kawachi, P. (2014). Quality assurance guidelines for open educational resources: TIPS framework. https:// www.open-ed.net/oer-quality/validation.pdf

Krajka, J. (2018). Finding quality resources for teachers online. In J. I. Liontas (Ed.), The TESOL encyclopedia of English language teaching. Wiley. https://doi.org/10.1002/9781118784235.eelt0279.

Luo, T., Hostetler, K., Freeman, C., \& Stefaniak, J. (2020). The power of open: Benefits, barriers, and strategies for integration of open educational resources. Open Learning: The Journal of Open, Distance and e-Learning, 35(2), 140-158. https://doi.org/10.1080/02680513.2019.1677222.

Open Education Week. (2020). GCC Library 2020 open education week - OER student survey. https:// gwcc.libguides.com/ld.php?content_id=52767526

Orton Grissett, J., \& Huffman, C. (2019). An open versus traditional psychology textbook: Student performance, perceptions, and use. Psychology Learning \& Teaching, 18(1), 21-35. https://doi. org/10.1177/1475725718810181.

Schaffhauser, D. (2020, September 14). Updated: Free resources for schools during COVID-19 outbreak. The Journal. https://thejournal.com/articles/2020/03/13/free-resources-ed-tech-companies-step-upduring-coronavirus-outbreak.aspx

Shams, S., Ahsan ul Haq, M., \& Waqar, Y. (2020). Open educational resources (OER) usage trends among university students of Pakistan. Education and Information Technologies. https://doi.org/10.1007/ s10639-020-10195-3.

Van Allen, J., \& Katz, S. (2020). Teaching with OER during pandemics and beyond. Journal for Multicultural Education. https://doi.org/10.1108/JME-04-2020-0027.

Wiley, D., \& Hilton, J. L., III. (2018). Defining OER-enabled pedagogy. The International Review of Research in Open and Distance Learning, 19(4), 133-147. https://doi.org/10.19173/irrodl.v19i4.3601.

Publisher's Note Springer Nature remains neutral with regard to jurisdictional claims in published maps and institutional affiliations.

Ferit Kılıçkaya graduated from language teacher training program and works as a Professor of English in the Department of Foreign Language Education at Burdur Mehmet Akif Ersoy University, Turkey. He has more than 20 years of experience in teaching English as a foreign language, and his main areas of interest include the use of technology in language learning and teaching, digital assessment, and teaching language skills.

Joanna Kic-Drgas graduated from linguistics and economics and works as an Assistant Professor in ESP in the Institute of Applied Linguistics at the Faculty of Modern Languages and Literature of the Adam Mickiewicz University in Poznań. She has 10 years of experience in teaching languages for specific purposes and has authored and co-authored papers focused on teaching methodology, intercultural communication, LSP/ ESP. 